\title{
Analysing Educational Waste in the Punjab Schools
}

\author{
MUHAMMAD RAFIQ
}

\begin{abstract}
This paper examines educational waste in the Punjab Public Schools. The paper focuses upon three areas: schools' internal efficiency, school capacity utilisation and student teacher ratio. By using cohort analysis technique, the paper measures waste in flows of students in the education cycle. The results show that repetition and dropout are more prevalent in class I and middle school classes. This implies that after having studied for five to six years in schools, a student finds themselves in a blind alley, not knowing where it all would end up. This also suggests that majority of the schools are located at large distance from the most of the population of the Punjab and students have to travel long distance for attending the schools. The under-utilisation of school capacity is more prevalent in rural area than that of urban areas and girls schools are more under-utilised than the boys schools. The under-utilisation is more widespread in boys schools of urban areas than the girls schools located in same vicinity and girls school in rural areas are more under-utilised than the boys schools. The pervasive theme emerged from results is that girls schools and teachers are mostly under-utilised. This reflects that disadvantage that girls face in Pakistan which may also cause under-utilisation of girls schools.
\end{abstract}

\section{INTRODUCTION}

The study of educational waste has not received due attention generally in Pakistan and particularly in the Punjab province. A few partial attempts are made in this regard [Khan and Siddiqui (1986); Khan, Siddiqui and Fazal (1986) and Bhati (1987)] which are limited in scope and suffer methodological problems. Moreover the objectives of these studies are not to address this issue. The lack of research on the topic is unfortunate. Many resources from the limited income of the country have been spent on this sector without significant increase in the literate population and no effort is made to address the issue of waste in the educational institutions. Since education sector in Pakistan suffers from under-investment and continued rapid population growth rate has made it more difficult to provide sufficient schools and teachers for increasing school age cohort [Sathar and Lloyd (1994)], therefore, choice left for the Punjab Government is to use the existing infrastructure of schools

Muhammad Rafiq is Deputy Chief Programmer at the Pakistan Institute of Development Economics, Islamabad.

Author's Note: I am grateful to Dr Gery Brown for his useful comments on an earlier draft of this paper. I am also thankful to the British Council for providing me the opportunity to work for the Punjab Educational Management Information System. 
efficiently. For this, an accurate monitoring and evaluation system for educational waste becomes essential. This type of system may help to assess the achievements and plan the future targets so that our new generations could receive minimum basic education. Studying this issue becomes more important when the efforts for the education for all in the largest province-Punjab are being made.

The objective of this paper is to examine the extent and pattern of educational waste in the Punjab schools. The paper is based on primary data collected through three Schools Censuses for the years 1993-94, 1994-95 and 1995-96 conducted by the Punjab EMIS centre. According to the censuses there were 65010 schools in year 1993-94, 66856 schools in year 1994-95, and 68498 schools in year 1995-96 of which data on enrolment, repeaters and teachers have been solicited.

The plan of paper is as follows: In Section II major components of educational waste are described followed by their detailed analysis and results. The conclusions and remarks are drawn in the last section.

\section{IDENTIFYING COMPONENTS OF EDUCATIONAL WASTE}

Any institution consumes inputs for producing output. If the institution is quite efficient, it will make adequate use of appropriate inputs to yield optimum output. If the system of the institution is not efficient it may waste some inputs in producing outputs. It will not use inputs efficiently because of high entropy. Similarly an educational system consumes inputs such as school building, school facilities and teachers to attain maximum enrolment and produce literate population. Enrolment provides an indication of the capacity of the education system to accommodate and educate students. If some schools do not use its capacity or a school does not have sufficient enrolment we can say that there is a wastage of school capacity. A school is also inefficient if it does not retain the students who got enrolled and later dropped out. Although schools solely are not responsible for dropout and there are other many factors as well which causes high dropouts. But the teachers absenteeism [Ehrenberg et al. (1991)], attitude of teachers, location and space of schools [World Bank (1980)] and lack of motivation to pupils for attending schools are also the factors responsible for high dropouts and students' achievements. The waste also exists in shape of repeaters. Similarly there could be many types of educational waste but we are focusing upon only three types in the present paper that are (i) poor schools' internal efficiency; (ii) low students-teacher ratio; and (iii) under-utilisation of schools capacity.

\subsection{Schools’ Internal Efficiency}

It has been argued that the Pakistan suffered set back of high dropout but there 
is a little evidence in the literature regarding the issue. There are a few attempts made in this regards as mentioned earlier. This section addresses this issue for the province of Punjab and measures waste level of students through the education cycle in the Punjab schools. The dropouts and repeaters are the quantitative measures of waste in flow of students. This section deals with these measures. In the following methodology is explained followed by the analyses.

We use the cohort analysis for tracing the flow of the students through entire education cycle. Application of this method for assessing wastage and measuring internal efficiency of education systems has been commonly accepted as one of the best tools. It is the graphic representation of student's flow as shown in Figure 1. Each box of the Figure 1 contains three arrows: one that angles up indicates the dropout rate from education system; one that angles down towards another box contains the promotion rates to the next class in the next years and the arrow going vertically down to a box shows the percentage of students repeating that grade in the next year. The enrolment are given inside the boxes.

The flow of students during an educational cycle depends solely on the four parameters: (i) the number of new entrants in the first class of the cycle; (ii) the dropouts in the different classes; (iii) the repetition in the different classes at the end of each year; and (iv) the promotion from one class to the next at the end of each year.

Here it may be useful to describe the formulae used in the analyses as reported in Figure 1. Therefore definition of the different parameters and transient rates of students through education cycle are given below:

$$
\begin{aligned}
S_{c, t}= & \text { students at class c, during the year } t . \\
P_{c+1, t+1}= & \text { passed number of students at class } \mathrm{c} \text { who during the following school } \\
& \text { year are advanced to the class } c+1 . \\
R_{c, t+1}= & \text { number of students repeating class c. These students who will stay in } \\
& \text { class } \mathrm{c} \text { during the year } t+1 \text { after having been in it during } t . \\
D_{c, t}= & \text { dropped number of students who dropout at class } c \text {, during school year } t . \\
p_{c, t}= & \text { promotion rate for class } \mathrm{c} \text {, or the proportion of students of class } \mathrm{c} \text { in } \\
& \text { year } t \text { who will be in class } c+1 \text { in the year } t+1 . \\
r_{c, t}= & \text { repetition rate for the class } c \text {, or the proportion of students of class } \mathrm{c} \\
& \text { during the year } t \text { who will be in the same class in the year } t+1 \\
d_{c, t}= & \text { dropout rate for the class } c \text { during the year } t .
\end{aligned}
$$

Now rates of promotion $\left(p_{c, t}\right)$, repetition $\left(r_{c, t}\right)$ and dropout $\left(d_{c, t}\right)$ may be written as:

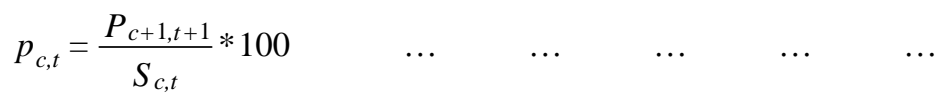


Fig. 1. Flow Cohort of Students in Punjab Schools Through School Years

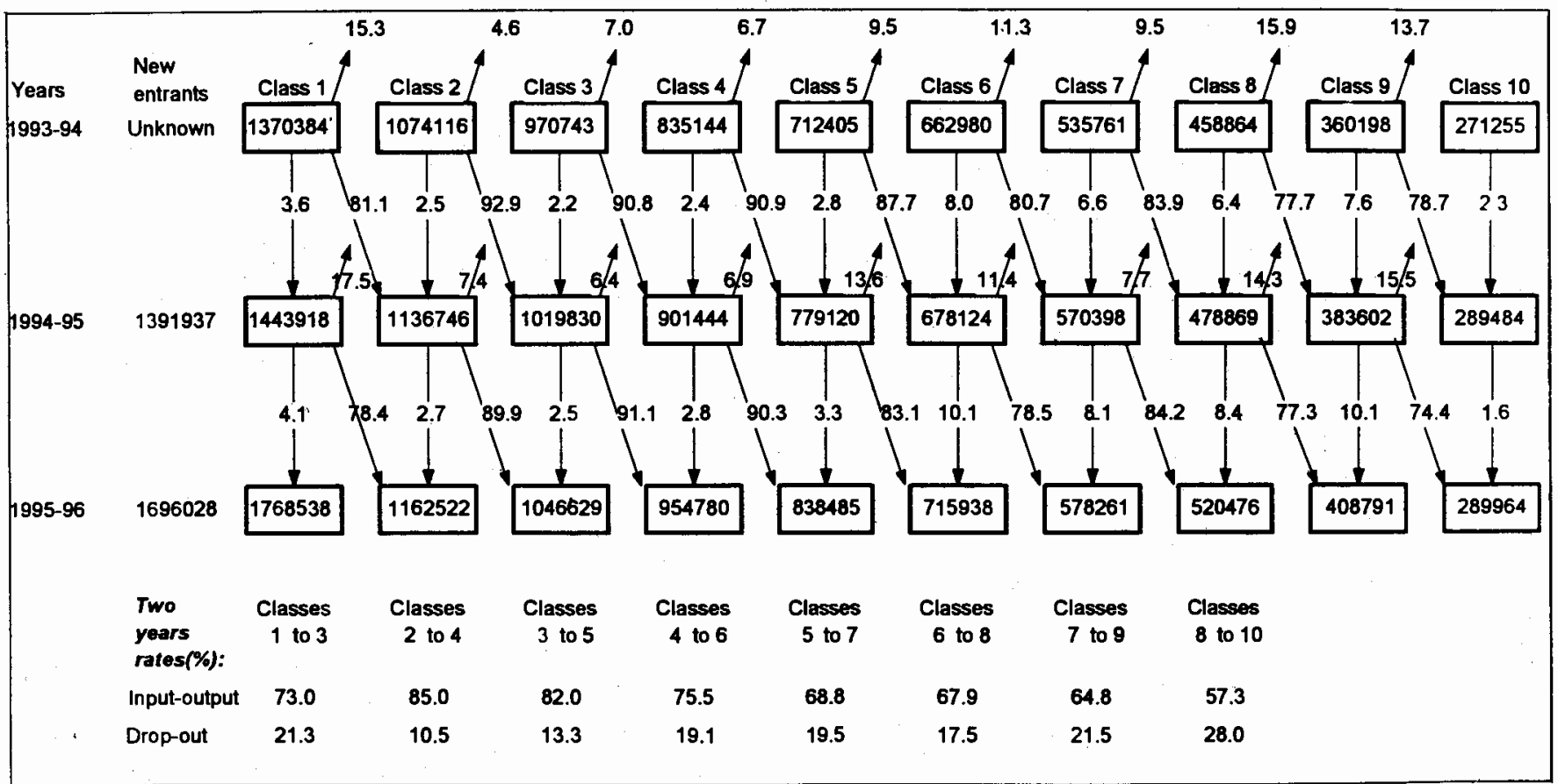

Source: Data is taken from EMIS Schools Censuses 1993-94, 1994-95 and 1995-96.

Note: Values along $\downarrow$ arrows shows repetition rates, values along $\downarrow$ arrows indicate promotion rates and the dropout rates (\%) are reported along $\nearrow$ arrows and enrolment are given in side the boxes. Values are rounded off up to first decimal place. Therefore, there may exist round off errors in the calculations. 


$$
\begin{aligned}
& \begin{array}{rlllll}
r_{c, t}=\frac{R_{c+1, t} * 100}{S_{c, t}} 100 & \ldots & \ldots & \ldots & \ldots & \ldots
\end{array} \\
& \begin{array}{lllllll}
d_{c, t}=\frac{D_{c, t}}{S_{c, t}} * 100 & \ldots & \ldots & \ldots & \ldots & \ldots & \text { (3) }
\end{array} \\
& \begin{array}{lllllll}
p_{c, t}+r_{c, t}+d_{c, t}=1 & \ldots & \ldots & \ldots & \ldots & \ldots & \text { (4) }
\end{array}
\end{aligned}
$$

Figure 1 provides the flow of Punjab students through class 1 to class 10 that contains the statistics concerning schools during the three years (1993-94, 1994-95 and 1995-96). Katchi class is ignored because some schools open admission for class 1 and also many parents prefer to keep children in private nursery schools or they coach them at their homes. When their children reach the age of class 1 , only then they are sent to school in class 1 directly. Therefore we may assume that all students enter the class 1 . Before presenting analyses it will be useful to explain the use of figure. The cohort goes on step by step through the cycle. Many students will be dropped out at various points along the way, other will be delayed by one or more repetitions. Figure 1 shows that 1,696,028 students entered class 1 during 1995-96 where they found 59079 (4.1 percent) from 1994-95 who were repeating class 1 . The Figure 1 further indicates that total 1443918 students including 1391937 new entrants were in class 1 in 1994-95. Out of these 1132031 (78.4 percent) were promoted to class 2 where they found 30692 (2.7 percent) and 252685 (17.5 percent) were dropped out.

The percentage distribution of repeaters, dropouts and promotees through different classes as reported in Figure 1 exhibits a fluctuation pattern. Figure 1 indicates that about 15.3 percent pupils of class 1 left the schools in the same year in which they entered this class during year 1993-94. Other who left the schools from their respective classes during year 1993-94 are 4.6 percent of class 2, 7.0 percent of class 3, 6.7 percent of class 4, 9.5 percent of class 5, 11.3 percent of class 6, 9.5 percent of class 7, 15.9 percent of class 8 , and 13.7 percent of class 9 . Figure 1 further shows that among children admitted to class 1 during 1993-94, 3.6 percent repeated the class 1 during next years 1994-95 and 81.1 percent were promoted to class 2. Similar pattern is observed in flow of student during year 1994-95 and 199596. According to the figure, the highest dropout rate during 1994-95 is from class 1 at 17.5 percent and second highest rate of dropout is 15.5 percent from class 9 .

The two year aggregate pattern of promotion and dropouts is also reported in the same Figure $1{ }^{1}$ The Figure indicates that the highest dropout rate(28 percent) and also the lowest promotion rate (57.3 percent) in the education cycle is observed

\footnotetext{
${ }^{1}$ The repetition and promotion rates for the next year are assumed same for the promotees and repeaters of previous year.
} 
among those who moved from class 8 to class 10 . The figure further shows that second highest dropout rate (21.5) occurred during the transition of students between class 7 to class 9 . The figure further shows about 73.0 percent of cohort leads to the class 3 and dropout during this movement is about 21.3 percent. Those who reaches from class 2 to class 4 are 85 percent and 10.5 percent are gone out of the system. Examination about other class can be made from the figure.

Significantly dropout and repetitions rates are more prevalent in the middle and high school classes except class 1 . This means that out of the small number who started middle and secondary school, a substantial number left the school prior to obtaining the middle school or high school certificate. This goes in line with Bhati (1987) who observes that one of the major factors which weakens the holding power of school is that the students, after having studied for five to six years in schools, finds themselves in a blind alley, not knowing where it all would end up. Another reasons of high dropout rates in these classes may be that these schools are located at large distance from the most of the population of the Punjab and students have to travel long distance for attending the schools.

Efficiency in the flow of students (input-output ratio) can be improved by reducing repetition and dropout rates. For this purpose, promotion policy may be examined in detail so that these ratios especially dropout rates can be reduced at all levels. A review of literature shows that repetition does not have positive effect on student achievements or quality of education [World Bank (1980)]. However failure of school system to retain students may be due to several other factors as well. Identification of those factor responsible for high dropout is very important to overcome this problem. There is a need to expand school networks, school facilities and quality of teachers. The paper submits that high dropout and repetition rates may also be a reflective of education system's weaknesses that could not retain pupils and suggests for promotion of motivation for increasing their stay in the schools.

\subsection{Capacity Utilisation of the Punjab Public Schools}

Establishing new schools is a time taking process that not only involves high capital cost but also needs dedication of administration. If established schools are not used effectively in sense that they do not achieve the minimum level of enrolment then it is a wastage of resource. However level of wastage of school resources may be a relative term. The schools are established keeping in view the needs of area and political requirements. A school infrastructure in some areas may be quite sufficient for 500 students and in some area it may not be sufficient for 200 students. Question arises whether a school having capacity of 500 students could get an enrolment of 500 students or not. If it does not, then what is the percentage of its utilisation. Here we need to draw a boundary line for the capacity utilisation of a school. If capacity of a school is assumed as a five class room unit with enrolment capacity of 200 students, it gives an average size 
of 40 pupils, a general standard set by the Government in primary schools [Ahmed et al. (1983)]. But we assume here that if a school has less than one hundred students, then school is under-utilised and more students can be admitted to the school.

Table 1 presents the percentage distribution of schools by region, gender and groups of enrolment in the schools. The groups of enrolment are made in such way that schools having more than or equal to one hundred students are kept in one group, schools having less than one hundred students are divided into three groups i.e. school with enrolment upto 25 students are kept in one group, schools having 26 to 50 students forms second group and the school consisting of 51 to 100 students constitute a third group, so that policy-makers could choose some focus groups for possible intervention. The salient features notable in Table 1 are that many institutions are under-utilised. This under-utilisation is more prevalent in rural areas than that of urban areas and girls schools are more under-utilised than the boys

Table 1

Percentage Distribution of Schools by Region, Gender and Schools' Capacity Utilisation

\begin{tabular}{|c|c|c|c|c|c|c|}
\hline \multirow{2}{*}{$\begin{array}{c}\text { Region and } \\
\text { Gender of Schools }\end{array}$} & \multicolumn{5}{|c|}{ Groups of Enrolment } & \multirow{2}{*}{$\begin{array}{l}\text { No. of } \\
\text { Schools }\end{array}$} \\
\hline & $<25$ & $26-50$ & $51-100$ & 101-200 & 200 & \\
\hline \multicolumn{7}{|l|}{ Urban } \\
\hline Boys & 11.00 & 18.86 & 18.86 & 17.27 & 34.02 & 3654 \\
\hline Girls & 6.19 & 11.55 & 19.79 & 23.52 & 38.95 & 2891 \\
\hline Mix & 15.94 & 15.94 & 20.29 & 23.19 & 24.64 & 69 \\
\hline Total & 8.95 & 15.63 & 19.28 & 20.06 & 36.07 & 6614 \\
\hline \multicolumn{7}{|l|}{ Rural } \\
\hline Boys & 15.62 & 22.91 & 27.43 & 20.20 & 13.83 & 34077 \\
\hline Girls & 16.97 & 27.51 & 28.10 & 16.81 & 10.61 & 23306 \\
\hline Mix & 20.22 & 29.78 & 28.09 & 15.73 & 6.18 & 178 \\
\hline Total & 16.18 & 24.79 & 27.70 & 18.81 & 12.5 & 57561 \\
\hline \multicolumn{7}{|l|}{ Total } \\
\hline Boys & 15.18 & 22.52 & 26.60 & 19.92 & 15.79 & 37731 \\
\hline Girls & 15.78 & 25.75 & 27.19 & 17.55 & 13.74 & 26197 \\
\hline Mix & 19.03 & 25.91 & 25.91 & 17.81 & 11.34 & 247 \\
\hline Total & 15.44 & 23.85 & 26.84 & 18.94 & 14.93 & 64175 \\
\hline
\end{tabular}

Source: Punjab Educational Management Information System (EMIS) schools census 1995-96.

Note: The Schools under control of The Punjab Government are included in the table and closed schools has been excluded. 
schools. The table further suggests that under-utilisation is more widespread in boys schools of urban area than the girls schools located in same vicinity and girls school in rural areas are more under-utilised than the boys schools.

The table shows that about 43.86 percent of urban school are under-utilised out of which, 8.95 percent are schools that have upto 25 students, 15.63 are those having 25 to 50 students and 19.28 percent that have 51 to 100 students. The table discloses that about 68.69 percent of rural schools are under-utilised of which 16.18 percent of the schools have upto 25 students, 24.79 percent schools have 26 to 50 student and 27.7 percent are those schools that have 51 to 100 students in a schools. On Punjab level, gender wise pattern is also assessed. Among the boys schools, 15.18 percent are those schools that have upto 25 students, 22.52 percent of the schools have 25 to 50 students. There are 26.60 percent schools that have enrolled 51 to 100 students. Among girls schools, there are 15.78 percent schools having upto 25 students, 25.67 percent schools contain 26 to 50 students and 27.19 percent of schools has 51 to 100 students. On overall level 15.44 percent of schools have upto 25 students, 23.85 percent schools are those schools that have 26 to 50 students and 26.84 percent schools have 51 to 100 students. The present level of school underutilisation may be high because of some schools are shelterless or has class room in poorly constructed school buildings. This section of paper submits that the existing strength of pupils in a schools may be a reflective of demand for low education i.e. less the demand of education by the people lower the enrolment rate. This suggests for promotion of motivation particularly to girls for raising level of schools capacity utilisation and restructuring or reform the existing infrastructure to make full utilisation of schools.

\subsection{Students-teacher Ratio}

The adequate number of teachers in a school is one of the indicators of quality education. This number should be up to a limit. Neither number of teachers in a school should be too high nor they should be too low. Since teachers' salary component of education expenditure constitutes most of the recurring expenditure, students-teacher ratio must be maintained as close to an acceptable norms as possible. This expenditure cannot be increased beyond limits. Therefore if studentsteacher ratio is maintained at an acceptable level say 30 to 40 students per teacher, enrolment can be improved by increasing the number of students per teacher where this ratio is below the desirable level without adversely affecting the quality of education and making heavy investment. We can say that wastage may also exist in those schools where students teacher ratio is not in acceptable range.

Table 2 gives the distribution of schools and teachers deployed in those schools by groups of students-teacher ratio, region and gender of school. The distribution is drawn in four groups of students-teacher ratio, groups are (i) those 
Table 2

Percentage Distribution of Schools and Teachers by Region, Gender of School and Students Teacher Ratio

\begin{tabular}{|c|c|c|c|c|c|}
\hline \multirow[b]{2}{*}{ Region and of Schools } & \multicolumn{4}{|c|}{ Students per Teacher } & \multirow[b]{2}{*}{ Total No. of Schools } \\
\hline & $*$ & $1-20$ & $21-30$ & $31+$ & \\
\hline \multicolumn{6}{|l|}{ Urban } \\
\hline \multicolumn{6}{|l|}{ Schools } \\
\hline Boys & 4.87 & 20.74 & 24.69 & 49.70 & 3654 \\
\hline Girls & 8.30 & 28.02 & 24.52 & 39.16 & 2891 \\
\hline Mix & 2.90 & 33.33 & 21.74 & 42.03 & 69 \\
\hline Total & 6.35 & 24.06 & 24.58 & 45.01 & 6614 \\
\hline \multicolumn{6}{|l|}{ Teachers } \\
\hline Boys & 0.27 & 17.52 & 31.86 & 50.35 & 33233 \\
\hline Girls & 0.44 & 20.89 & 28.92 & 49.75 & 29005 \\
\hline Mix & 0.00 & 31.72 & 31.12 & 37.16 & 331 \\
\hline Total & 0.35 & 19.16 & 30.50 & 50.00 & 62569 \\
\hline \multicolumn{6}{|l|}{ Rural } \\
\hline \multicolumn{6}{|l|}{ Schools } \\
\hline Boys & 4.61 & 26.28 & 29.18 & 39.93 & 34077 \\
\hline Girls & 7.57 & 41.24 & 23.58 & 27.61 & 23306 \\
\hline Mix & 3.93 & 24.16 & 28.09 & 43.82 & 178 \\
\hline Total & 5.81 & 32.33 & 26.91 & 34.95 & 57561 \\
\hline \multicolumn{6}{|l|}{ Teachers } \\
\hline Boys & 0.37 & 26.29 & 35.15 & 38.18 & 134690 \\
\hline Girls & 0.48 & 41.56 & 27.78 & 30.17 & 83952 \\
\hline Mix & 0.00 & 24.84 & 33.85 & 41.32 & 455 \\
\hline Total & 0.41 & 32.14 & 32.33 & 35.12 & 219097 \\
\hline \multicolumn{6}{|l|}{ Total } \\
\hline \multicolumn{6}{|l|}{ Schools } \\
\hline Boys & 4.64 & 25.75 & 28.74 & 40.88 & 37731 \\
\hline Girls & 7.65 & 39.78 & 23.69 & 28.88 & 26197 \\
\hline Mix & 3.64 & 26.72 & 26.32 & 43.32 & 247 \\
\hline Total & 5.86 & 31.48 & 26.67 & 35.99 & 64175 \\
\hline \multicolumn{6}{|l|}{ Teachers } \\
\hline Boys & 0.35 & 24.56 & 34.50 & 40.59 & 167923 \\
\hline Girls & 0.47 & 36.25 & 28.08 & 35.20 & 112957 \\
\hline Mix & 0.00 & 27.74 & 32.70 & 39.57 & 786 \\
\hline Total & 0.40 & 29.26 & 31.92 & 38.42 & 281666 \\
\hline
\end{tabular}

Source: Punjab EMIS census 1995-96.

Note: The schools under control of the Punjab government are included in the table and closed schools are excluded.

* These are the schools where teachers or students or both are zero. 
schools where either students or teachers are zero; (ii) those schools where there are 1 to 20 students for a teacher; (iii) those schools where 21 to 30 students for a teacher are enrolled; and (iv) the schools having a teacher for 31 students or more. The schools having one to twenty students per teachers may be identified to be underutilised and the school having one teacher for twenty to thirty students are moderate in the utilisation of their teachers and improvement is possible in those schools. The schools having one teacher for 31 students or more may be declared as those schools fully utilising their teachers.

The Table 2 shows that 20.74 percent boys schools of urban areas having 17.52 percent teachers of the total are under-utilising their teachers as compared to 28.02 percent girls urban schools with 20.89 percent teachers. Evidence from Table 2 further indicates that there are 26.28 percent boys schools along with 26.29 teachers in rural areas that are under-utilising their teachers and 41.24 percent of girls school with 41.56 percent of teacher in rural area are under-using their teachers. According to the table there are 24.06 percent urban schools where 32.33 percent of teachers are deployed and rural area schools constitute 32.33 percent containing 33.14 percent of teachers are under-utilised their teachers. It means under-utilisation is more diffused in the rural areas of the Punjab. On the Punjab level, girls schools (39.78 percent) are under-utilising their teachers that have 36.25 percent of the total teachers as compared to boys schools (25.75) which have 24.56 percent teachers. This means that under-utilising of teachers by the girls school is more prevalent than the boys schools in the Punjab as well as urban and rural areas. The table implies that prevalence of under-utilisation of teachers exist in the Punjab schools. The intervention is required to improve the student teacher ratio. The waste could also be minimised by redeploying teacher from under-enrolled school to over-enrolled schools.

\section{CONCLUSIONS}

The study has examined the extent of diffusion of educational waste in the Punjab education system. The study witnessed that sizeable institutions are underutilised. This under-utilisation is more prevalent in rural area than that of urban areas and girls schools are more under-utilised than the boys schools. The under-utilisation is more widespread in boys schools of urban area than the girls schools located in same vicinity and girls school in rural areas are more under-utilised than the boys schools. The pervasive theme emerged from results is that girls schools and teachers are mostly under-utilised. This reflects that disadvantage that girls face in Pakistan. Parents prefer sons to daughters for sending them to schools [Sathar and Lloyd (1994); Ali (1989) and Sathar (1987)] which may also cause under-utilisation of girls schools. The intervention is required to improve the students teacher ratio which may be minimised by redeploying teacher from under-enrolled school to over-enrolled schools. 
Significantly dropout and repetition rates are more prevalent in the middle and high school classes except class 1 where the dropout rate is the highest. This means that out of the small who started middle or high school education, a substantial number left the schools prior to obtaining the middle schools or high school certificates. One of the reasons of high dropout rates in these classes may be that these school are located at large distance from the most of the population of the Punjab and students have to travel long distance to attend the schools. One thing is clear; on overall basis educational waste is sizeable, a lot of the dropout of each class -adding to tremendous wastage. Efficiency in the flow of students(input-output ratio) can be improved by reducing repetition and dropout rates. For this purpose, promotion policy should be examined in detail so that these ratios, especially dropout rates can be reduced at all levels in general and early grades in particular. A review of literature shows that repetition does not have positive effect on student achievements or quality of education. However failure of school system's to retain students may be due to several factors. Identification of those factor responsible for high dropout is very important to overcome this problem. There is a need to expand school networks, school facility and quality of teachers. The paper submits that high dropout and repetition rate may be a reflective of education system's weaknesses that could not to retain them and suggests for promotion of motivation for increasing their stay in schools.

Keeping in view the important of human development, Pakistan needs to improve the quality of existing schools in terms of efficiency and effectiveness, provide special motivation to girls [Mehmood and Zahid (1992)] and reduce the relative cost of attendance for girls [Sathar and Lloyd (1994)].

\section{REFERENCES}

Ali, Syed Mubashir (1989) Does Son Preference Matter? Journal of Biosocial Science 214: 399-408.

Ahmed, Salehuddin et al. (1983) Primary Education Network in Bangladesh. Dhaka: National Foundation for Research on Human Resource Development.

Bhati, Mukhtar Ahmad (1987) Secondary Education in Pakistan. Perspective Planning. Islamabad: Academy of Education Management and Planning. (Education Development Series No.2.)

Ehrenberg, Ronal G. et al. (1991) School District Leave Policies, Teacher Absenteeism and Student Achievement. The Journal of Human Resources 26:1 73-105.

Khan, Shahrukh R., Naushin Mahmood and Rehana Siddiqui (1986) An Analysis of School Level Enrolment, Dropout and Output in Pakistan. Islamabad: Pakistan Institute of Development Economics. (Research Reports Series No. 149.) 
Khan, Shahrukh R., Rehana Siddiqui and Fazal Hussain (1986) An analysis of School Level Dropout Rates and Output in Pakistan: Supply and Demand Side Consideration (1970-71-1982-83). Islamabad: Pakistan Institute of Development Economic. (Mimeographed.)

Mahmood, Naushin, and G. M. Zahid (1992) Measuring the Education Gap in Primary and Secondary Schooling in Pakistan. The Pakistan Development Review 31:4 729-740.

Sathar, Zeba A. (1987) Sex Differentials in Mortality: A Calory of Son Preference? The Pakistan Development Review 26:4 555-568.

Sathar, Zeba A., and Synthia B. Lloyd (1994) Who Gets Primary Schooling in Pakistan: Inequality among and within Families. The Pakistan Development Review 33:2 103-134.

World Bank (1980) Education. Washington, D. C.: The World Bank. (Sector Policy Paper.) 